\title{
STUDI KELAYAKAN LAHAN BUDIDAYA RUMPUT LAUT Eucheuma cottonii di KECAMATAN BLUTO SUMENEP MADURA JAWA TIMUR (Feasibility Study of Eucheuma Cottonii Seaweed Farming in Bluto Subdistrict of Sumenep Madura East Java)
}

\author{
Abdul Qadir Jailani*, Endang Yuli Herawati dan Bambang Semedi \\ Jurusan Budidaya Perairan, Fakultas Perikanan dan Ilmu Kelautan, Universitas Brawijaya, \\ Jl. Veteran, Malang 65145. \\ *Penulis korespondensi. No Tel :085852554554 ; Email : aqodirjailani@gmail.com.
} Diterima: 23 Desember 2014

Disetujui: 7 April 2015

\begin{abstract}
Abstrak
Budidaya rumput laut di Kecamatan Bluto, Kabupaten Sumenep, Jawa Timur, mempunyai kontribusi bagi perekonomian masyarakat pesisir, akan tetapi terdapat kegiatan perikanan seperti penangkapan dan pengolahan hasil laut yang berdampak pada degradasi kualitas air yang berpengaruh langsung kepada hasil produksi rumput laut. Tujuan dari penelitian ini adalah untuk mengetahui lokasi baru pengembangan kegiatan budidaya rumput laut secara berkelanjutan yang terbebas dari kegiatan masyarakat dengan melihat faktor ekologis dan daya dukung perairan di Kecamatan Bluto. Metode yang digunakan mengukur kesesuaian ekologis meliputi suhu, kecerahan, kedalaman, kecepatan arus, kondisi dasar perairan, salinitas, DO, nitrat, ortofosfat, $\mathrm{pH}$, BOD, dan COD, serta estimasi hama dan penyakit rumput laut. Selanjutnya data diskoring untuk menentukan kelas kesesuaian dengan pendekatan SIG. Daya dukung perairan di analisis dengan menghitung 60\% dari jumlah kawasan yang sesuai. Hasil penelitian menunjukkan bahwa perairan Bluto memiliki potensi lahan pengembangan rumput laut berdasarkan kelas S1 (sangat sesuai) dan S2 (sesuai bersyarat) seluas 770,19 ha, dan mampu menampung maksimal 42.788 unit rakit rumput laut. Hama dan penyakit yang teridentifikasi di perairan Bluto adalah ikan baronang (Siganus. sp), ice-ice, lumut (Chaetomorpha crassa), dan teritip (Chthamalus stellatus).
\end{abstract}

Kata kunci: daya dukung perairan, faktor ekologi, kualitas air, kegiatan perikanan, rumput laut.

\begin{abstract}
Seaweed farming in the subdistrict Bluto, District Sumenep, East Java, has significant contribution in the economy of coastal communities, but there are fishing activities like catching up and marine product proccessing that have negative impact to the degradation of water quality and then directly affect the production of seaweed. The purpose of this study is find new location of the development of seaweed farming activities in a sustainable manner that is free from of community activities with a view of ecological factors and carrying capacity of the waters in the analies of the subdistrict Bluto. The method was used to analyze its ecological suitability includes temperature, transparency, depth, current velocity, bottom water condition, salinity, DO, Nitrite, ortophosphate, $p H, B O D$, and COD, also evaluation of the predators and diseases seaweed. Then, the data is scored to determine its suitability class with SIG approach. Environmental carrying capacity is analyzed by determining 60\% of suitable sites. The result showed that Bluto territorial waters was potential for seaweed farming development as it was in Class S1(very suitable) and S2 (suitable with conditions) about 770.19 ha and able to contain maximum 42,788 units of seaweed floated bamboos. Predators and diseases identified in Bluto waters are rabbitfishes (Siganus. sp), ice-ice disease, green algae (Chaetomorpha crassa), and Poli's stellate barnacle (Chthamalus stellatus).
\end{abstract}

Keywords: carrying capacity, ecological factors, water quality, fishing activities, sea grass.

\section{PENDAHULUAN}

Perikanan dan akuakultur menyediakan pangan yang besar dan pendapatan bagi negaranegara yang mempunyai pesisir dan merupakan sumber kehidupan dari 3 milyar orang (Amosu dan Alberto, 2012). Rumput laut merupakan tanaman yang mengagumkan dilaut dan merupakan tanaman yang sangat berguna. Rumput laut tumbuh di perairan dangkal (Mohammed, 2013). Rumput laut juga dapat dimanfaatkan sebagai penyerap nutrien yang berlebihan dari buangan tambak perikanan (Yousef, 2012)

Kabupaten sumenep merupakan daerah penghasil rumput laut terbesar di Jawa Timur. Wilayah pantai yang landai, ekosistem terumbu karang dan perairan laut yang relatif tenang memacu perkembangan usaha budidaya rumput laut, dan dengan luas areal budidaya 5.795 ha dapat menghasilkan 3.224,70 ton rumput laut per tahun (Anonim, 2008). 
Pengelolaan dan pengembangan di Kecamatan Bluto Sumenep untuk budidaya rumput laut telah menjadi agenda pemerintah. Pengelolaan dan pengembangan harus didasarkan kepada daya dukung lingkungannya dan kelayakan pemanfaatan lahannya untuk budidaya rumput laut. Hal ini disebabkan di daerah Bluto sangat rentan terhadap perubahan lingkungan sekelilingnya seperti kegiatan penangkapan dan pengolahan perikanan oleh masyarakat. Pengembangan yang dilakukan harus tetap dalam koridor daya dukung lingkungannya dan sesuai dengan kegunaan lahannya serta sesuai dengan keinginan masyarakatnya (Zoeraini, 1992). Pengembangan kawasan budidaya rumput laut belum teridentifikasi secara menyeluruh. Permasalahan rumput laut yang ada di Indonesia adalah belum adanya peta kawasan pengembangan tata ruang yang ditunjang daya dukung lingkungan, selain itu adanya kesenjangan informasi masyarakat utamanya informasi pasar, informasi teknologi, sumber bibit, hama dan penyakit, musim, perawatan, sampai pasca panen dan sumber permodalan. Tujuan dari penelitian ini adalah untuk mengetahui lokasi pengembangan kegiatan budidaya rumput laut secara berkelanjutan dengan melihat faktor ekologis, daya dukung dan dampak dari masyarakat terhadap budidaya rumput laut diperairan Kecamatan Bluto.

\section{METODE PENELITIAN}

\section{Waktu dan Lokasi}

Penelitian ini dilaksanakan di Kecamatan Bluto Kabupaten Sumenep dan waktu penelitian dilaksanakan pada bulan September 2013.

Tabel 1. Sistem penilaian kesesuaian perairan lokasi budidaya rumput laut.

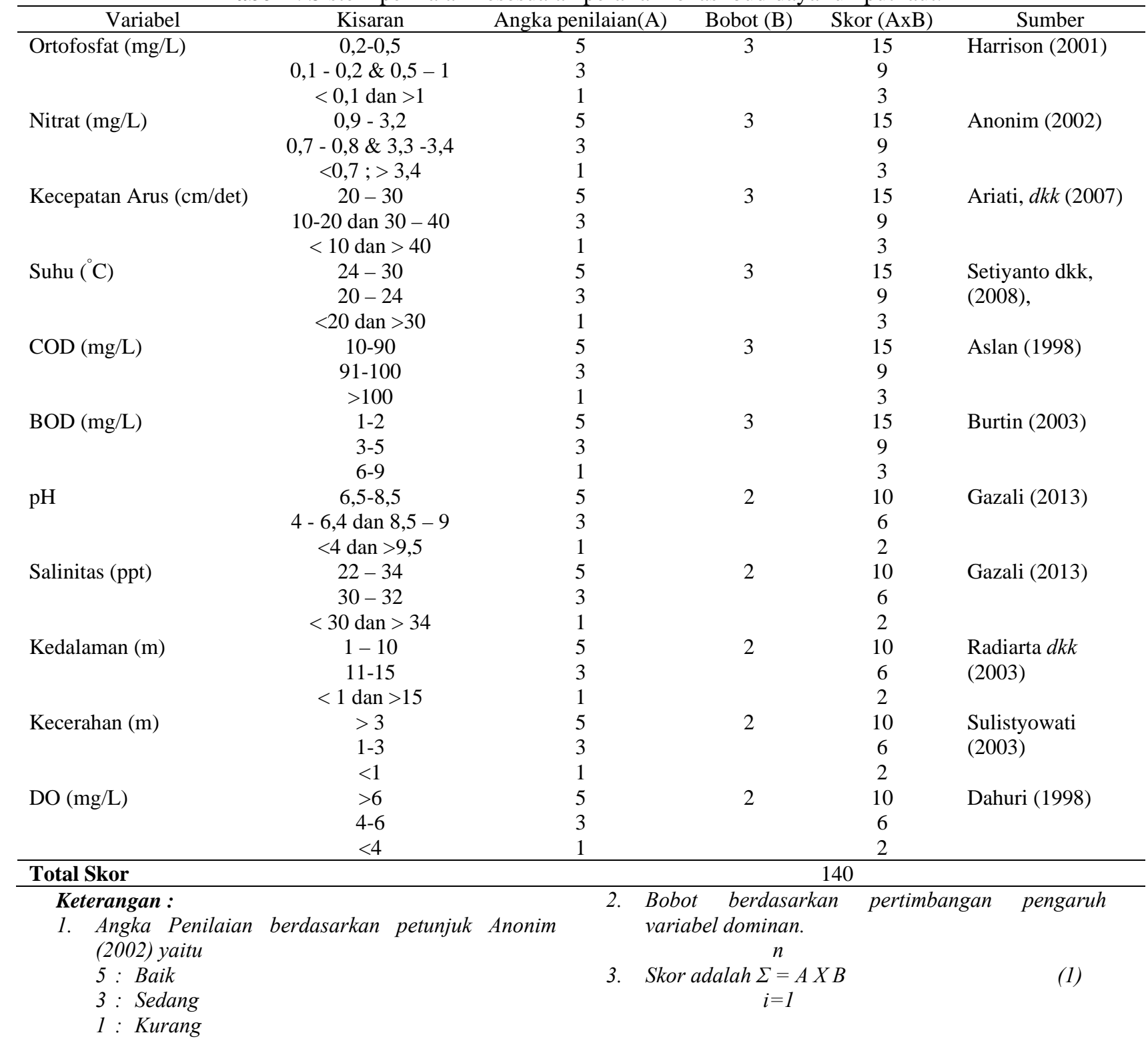


Pengambilan data meliputi data ekologi perairan, skoring, daya dukung lahan, wawancara, serta penggunaan software Arcgis untuk pembuatan kawasan yang sesuai dalam budidaya rumput laut secara ekologi perairan.

\section{Ekologi Perairan}

Ekologi perairan diambil pada 15 titik lokasi perairan di sepanjang kecamatan Bluto, yang meliputi: suhu, kecerahan, kedalaman, kecepatan arus, kondisi dasar perairan, salinitas, DO, Nitrat, Ortofosfat, pH, BOD, dan COD, sedangkan hama dan penyakit diperoleh dengan visualisasi atau identifikasi langsung di lokasi. Parameter lingkungan selanjutnya di skoring untuk menentukan nilai kesesuaian lahan budidaya rumput laut, nilai skoring dapat dilihat pada Tabel 1.

Hasil evaluasi dari sistem penilaian kesesuaian lokasi bagi budidaya rumput laut diperlihatkan pada Tabel 2. Selanjutnya nilai yang diperoleh dijadikan input untuk pembuatan kawasan yang sesuai dengan menggunakan Arcgis 9.3.

\section{Daya Dukung Lahan}

Estimasi daya dukung lingkungan perairan akan menunjukkan berapa unit rakit yang boleh ditanam dalam luasan area yang telah ditentukan. Untuk menganalisis daya dukung lingkungan menggunakan pendekatan dari formulasi yang dikemukakan Soselisa (2006) dalam Amarulah (2007) di mana untuk menduga daya dukung lingkungan adalah membandingkan luas suatu kawasan yang digunakan dengan luasan unit metode budidaya rumput laut. perhitungan daya dukung lahan menggunakan rumus:

$D=\frac{L K L}{L U M}$

Di mana :

LKL : adalah luas kapasitas kesesuaian lahan
Tabel 2. Evaluasi penilaian kesesuaian perairan untuk lokasi budidaya rumput laut.

\begin{tabular}{llll}
\hline No. & $\begin{array}{c}\text { Kisaran nilai } \\
(\text { Skor })^{1)}\end{array}$ & $\begin{array}{c}\text { Tingkat } \\
\text { kesesuaian }^{2)}\end{array}$ & \multicolumn{1}{c}{ Evaluasi/S } \\
\hline 1. & $119-140 \%$ & S1 & Sangat Sesuai \\
2. & $89-110 \%$ & S2 & Sesuai \\
3. & $67-88 \%$ & S3 & Sesuai Bersyarat \\
4. & $<66 \%$ & TS & Tidak Sesuai \\
\hline
\end{tabular}

Keterangan : 1) : Modifikasi. 2) : Anonim (1996)

LUM : adalah luasan unit metode

D : adalah koefisien budidaya efektif (60\%)

\section{Wawancara}

Dampak budidaya terhadap lingkungan dan produksi perikanan budidaya telah menjadi isu penting dalam beberapa tahun terakhir (Phillips, 1990). Aktivitas masyarakat pesisir berdampak negatif pada lingkungan sekitarnya, oleh sebab itu perlu diketahui aktivitas yang ada di lokasi yang dapat mengganggu kegiatan budidaya. Wawancara meliputi kegiatan perikanan dan pengolahan yang ada di lokasi serta konflik kepentingan. Selanjutnya dibuat peta lokasi yang sesuai untuk kegiatan budidaya rumput laut..

\section{HASIL DAN PEMBAHASAN}

Pengukuran kualitas perairan diperoleh bahwa lokasi budidaya di perairan Bluto masih bagus pada beberapa titik koordinat, akan tetapi ada juga titik nilai yang menunjukkan skor kurang bagus. Hal ini diduga pada beberapa lokasi di perairan Bluto mempunyai tingkat pencemaran yang tinggi, sebagai contoh pada koordinat $(113,8121,-7,1330$ dan 113,8095, -7,1351). Hasil pengukuran parameter kualitas air yang dilakukan pada 15 titik pada pukul 11.00-13.00 WIB di perairan Bluto dapat dilihat pada Tabel 3.

Tabel 3. Hasil pengukuran kualitas air.

\begin{tabular}{|c|c|c|c|c|c|c|c|c|c|c|c|c|c|}
\hline \multicolumn{2}{|c|}{ Koordinat } & \multirow{2}{*}{$\begin{array}{l}\text { BOD } \\
(\mathrm{mg} / \mathrm{L})\end{array}$} & \multirow{2}{*}{$\begin{array}{l}\text { COD } \\
(\mathrm{mg} / \mathrm{L})\end{array}$} & \multirow{2}{*}{$\begin{array}{c}\mathrm{DO} \\
(\mathrm{mg} / \mathrm{L})\end{array}$} & \multirow{2}{*}{$\begin{array}{c}\text { Kecepa- } \\
\text { tan arus } \\
\mathrm{cm} / \text { det }\end{array}$} & \multirow{2}{*}{$\begin{array}{l}\text { Kece- } \\
\text { rahan } \\
(\mathrm{m})\end{array}$} & \multirow{2}{*}{$\begin{array}{c}\text { Keda- } \\
\text { laman } \\
(\mathrm{m})\end{array}$} & \multirow{2}{*}{$\begin{array}{l}\text { Nitrat } \\
(\mathrm{mg} / \mathrm{L})\end{array}$} & \multirow{2}{*}{$\begin{array}{c}\text { PO4 } \\
\text { (mg/L) }\end{array}$} & \multirow{2}{*}{$\mathrm{pH}$} & \multirow{2}{*}{$\begin{array}{l}\text { Salinitas } \\
\text { (\%) }\end{array}$} & \multirow{2}{*}{$\begin{array}{l}\text { Suhu } \\
\left({ }^{\circ} \mathrm{C}\right)\end{array}$} & \multirow{2}{*}{$\begin{array}{l}\text { Skor } \\
\text { (\%) }\end{array}$} \\
\hline $\mathrm{x}$ & $\mathrm{Y}$ & & & & & & & & & & & & \\
\hline 113,8121 & $-7,1330$ & 6,3 & 110 & 6,94 & 6,0 & 0,6 & 0,9 & 2,9 & 0,58 & 7,5 & 30 & 31,6 & 70 \\
\hline 113,8095 & $-7,1351$ & 5,4 & 114 & 7,24 & 6,4 & 1,3 & 1,7 & 3,5 & 0,49 & 7,5 & 30 & 31,5 & 72 \\
\hline 113,8122 & $-7,1392$ & 5,5 & 92 & 6,96 & 9,3 & 1,3 & 2,0 & 4,0 & 0,56 & 7,2 & 32 & 30,6 & 78 \\
\hline 113,8087 & $-7,1416$ & 5,1 & 94 & 6,92 & 11,7 & 1,5 & 2,7 & 4,2 & 0,45 & 7,2 & 31 & 30,1 & 90 \\
\hline 113,8028 & $-7,1430$ & 5,3 & 80 & 6,80 & 23,7 & 1,5 & 3,1 & 6,3 & 0,34 & 7,3 & 30 & 30,0 & 114 \\
\hline 113,7699 & $-7,1247$ & 2,5 & 50 & 6,74 & 7,2 & 0,6 & 1,0 & 2,2 & 0,29 & 7,2 & 33 & 31,4 & 112 \\
\hline 113,7662 & $-7,1258$ & 2,3 & 15 & 7,10 & 6,8 & 1,0 & 1,6 & 2,8 & 0,26 & 7,3 & 33 & 31,3 & 112 \\
\hline 113,7680 & $-7,1276$ & 2,0 & 18 & 7,06 & 13,0 & 1,2 & 1,9 & 3,0 & 0,17 & 8,0 & 32 & 31,9 & 102 \\
\hline 113,7715 & $-7,1296$ & 1,7 & 20 & 6,96 & 12,0 & 1,4 & 2,3 & 1,3 & 0,16 & 7,5 & 33 & 31,0 & 112 \\
\hline 113,7750 & $-7,1321$ & 1,3 & 25 & 7,08 & 22,1 & 1,3 & 3,3 & 1,1 & 0,11 & 7,7 & 34 & 30,4 & 118 \\
\hline 113,7254 & $-7,1175$ & 1,4 & 16 & 5,00 & 6,0 & 1,0 & 1,2 & 0,7 & 0,16 & 7,5 & 34 & 30,4 & 92 \\
\hline 113,7286 & $-7,1206$ & 3,0 & 40 & 7,06 & 12,0 & 1,3 & 2,2 & 0,7 & 0,21 & 7,3 & 31 & 30,8 & 96 \\
\hline 113,7214 & $-7,1233$ & 1,9 & 21 & 7,30 & 17,2 & 1,4 & 2,5 & 0,9 & 0,17 & 7,0 & 32 & 31,0 & 99 \\
\hline 113,7275 & $-7,1250$ & 1,2 & 17 & 6,00 & 22,8 & 1,3 & 2,7 & 0,1 & 0,21 & 6,9 & 32 & 30,8 & 104 \\
\hline 113,7243 & $-7,1252$ & 1,1 & 16 & 7,10 & 25,3 & 1,6 & 2,9 & 0,1 & 0,11 & 7,1 & 35 & 30,4 & 98 \\
\hline
\end{tabular}




\section{Ekologi Perairan}

Nilai BOD di lokasi berkisar antara 1,1 - 6,3 mg/L, pada beberapa lokasi nilai BOD ditenggarai melebihi batas optimal 1-2 mg/L (Agustiningsih, 2012). Perbedaan nilai ini dikarenakan perairan Bluto rentan akan masukan limbah baik dari rumah tangga, pabrik, dan pertanian. Lokasi budidaya rumput laut di harapkan jauh dari sumber pencemar karena akan membuat rumput laut menjadi kerdil, rumput laut akan dilapisi cairan yang berkilau seperti pelangi pada bagian thallus sehingga daya serap unsur hara terganggu.

COD merupakan ukuran bagi tingkat pencemaran di suatu wilayah oleh bahan organik. Nilai COD di Bluto berkisar 15-114 mg/L, nilai tersebut terlalu tinggi atau masuk kategori tercemar. Bluto termasuk daerah yang sebagian besar aktivitas penduduknya adalah perikanan tangkap, budidaya, pertanian, dan pengolahan hasil tangkapan skala rumah tangga dan pabrik yang sebagian besar limbahnya di buang langsung ke laut.

Seperti halnya tumbuhan lainnya, rumput laut membutuhkan oksigen untuk kegiatan fotosintesis. Oksigen terlarut di lokasi penelitian berkisar antara 5-7,24 mg/L. Nilai oksigen terlarut terendah berkisar $<5 \mathrm{mg} / \mathrm{L}$, sebab jika oksigen terlarut lebih rendah dari nilai tersebut dapat diindikasikan perairan tersebut mengalami gangguan kekurangan oksigen, hal tersebut terjadi akibat kenaikan suhu pada siang hari, malam hari akibat respirasi organisme air, juga disebabkan oleh adanya lapisan minyak di atas permukaan air dan masuknya limbah organik yang mudah larut (Kamlasi, 2008).

Arus mempunyai peranan penting dalam pertumbuhan rumput laut. Jika arus terlalu pelan maka akan mengganggu penyerapan zat hara yang berada di perairan, selain itu arus yang pelan akan berdampak pada epifit-epifit yang tumbuh menempel pada rumput laut akan semakin banyak sehingga dapat menjadi kompetitor dalam mendapatkan nutrien (Arisandi, 2012). Kecepatan arus di lokasi berkisar 6-25,3 cm/dtk, rekomendasi budidaya rumput laut sebaiknya $>10 \mathrm{~cm} /$ detik. Di Bluto lokasi yang sesuai untuk budidaya rumput laut berjarak minimal $300 \mathrm{~m}$ dari bibir pantai karena arus yang lebih kencang.

Nilai kecerahan yang sesuai untuk pertumbuhan rumput laut menurut (Radiarta dkk, 2003) adalah $>3 \mathrm{~m}$. Kisaran nilai kecerahan di perairan Bluto adalah 0,6-1,6 m, parameter kecerahan dinilai kurang mendukung untuk kegitan budidaya rumput laut. Substrat lumput berpasir membuat tingkat kecerahan dilokasi rendah.

Kedalaman laut di perairan Bluto antara 0,93,3 m, dapat diasumsikan bahwa perairan bluto termasuk perairan yang landai. Nilai tersebut masih dalam kisaran yang dapat ditolerir oleh pertumbuhan rumput laut.

Nitrat di lokasi penelitian diperoleh kisaran nilai $0,1-6,3 \mathrm{mg} / \mathrm{L}$, nilai tersebut terbilang terlalu tinggi yang mengindikasikan bahwa perairan bluto subur. Kesuburan perairan untuk kegiatan budidaya harus pada kisaran optimal. Jika nitrat terlalu tinggi akan berdampak pada pertumbuhan rumput laut karena memunculkan alga-alga sebagai kompetitor dalam mendapatkan nutrisi.

Ortofosfat berkisar 0,1-0,58 mg/L. Nilai ini terbilang terlalu tinggi untuk suatu perairan. Sama halnya seperti nitrat keberadaan ortofosfat bersifat pembatas bagi pertumbuhan rumput laut, terkait dengan tingkat kesuburan perairan. Perairan Bluto terbilang subur dikarenakan terdapat banyak masukan bahan organik dari darat, pertanian, limbah RT dan pabrik juga peternakan.

Nilai pH di perairan Bluto diperoleh kisaran 6,9-8. Nilai $\mathrm{pH}$ tersebut masih dalam kisaran normal. Ukuran $\mathrm{pH}$ berpengaruh pada rendemen karaginan rumput laut. Menurut Harahap dkk (2011), pH 7,5-8,5 menunjukkan peningkatan rendemen karaginan dan menurun pada nilai $\mathrm{pH} 9$.

Hasil pengukuran salinitas di lokasi berkisar antara 30-35 ppt dan nilai tersebut masih dalam batas normal. Nilai salinitas 30-35 \% dapat meningkatkan jumlah sel, pertumbuhan, dan rendemen karaginan rumput laut (Arisandi, 2011). Hasil pengukuran kualitas air diperoleh kisaran suhu di lokasi $29-33{ }^{\circ} \mathrm{C}$ yang tergantung musim. Saat musim kemarau nilai suhu dapat mencapai 34 ${ }^{\circ} \mathrm{C}$. Nilai suhu tersebut masih dalam batas normal yang bisa ditoleransi oleh rumput laut. Teknik budidaya yang tepat menjadi faktor pembatas dalam peningkatan produksi, umumnya di Bluto menggunakan rakit apung yang sebagian thallus rumput laut muncul ke permukaan sehingga terpapar langsung oleh sinar matahari yang mengakibatkan thallus menjadi pucat dikarenakan ketinggian nilai suhu permukaan laut. Selanjutnya rumput laut yang pucat akan mudah putus hanyut terbawa arus.

\section{Hama dan Penyakit}

Hasil pengamatan hama dan penyakit diidentifikasi Teritip (Chthamalus stellatus), Ikan Baronang (siganus sp.), Ice-ice, dan Lumut (Chaetomorpha crassa). Masalah hama penyakit yang paling besar di lokasi A yaitu lumut yang tumbuh subur menempel pada thallus. Keberadaannya diduga karena kesuburan perairan di kawasan tersebut.

\section{Kesesuaian Lahan}

Parameter lingkungan yang sudah diskoring berdasarkan nilai pengukuran di lokasi selanjutnya 

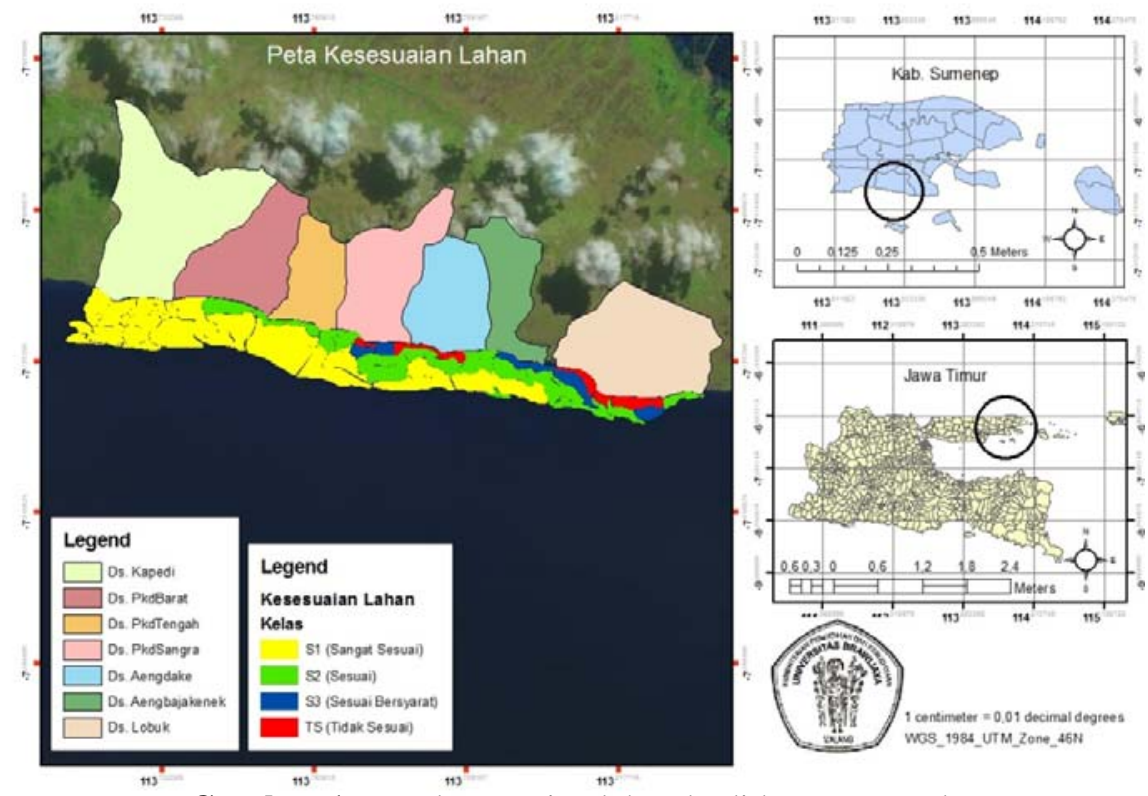

Gambar 1. Peta kesesuaian lahan budidaya rumput laut.

diolah agar mendapatkan kawasan yang sesuai untuk kegiatan budidaya rumput laut menggunaan bantuan software Arcgis yang dapat dilihat pada (Gambar 1).

Penilaian kesesuaian lahan sebagai indikator penentu dalam pengembangan kegiatan budidaya rumput laut di Kecamatan Bluto yang didasarkan atas beberapa parameter kesesuaian ekologi perairan dan berdasarkan hasil evaluasi kesesuaian perairan untuk budidaya rumput laut dari masingmasing kategori kesesuaian. Hasil perhitungan lahan sebagai berikut lahan yang sesuai sebanyak 770,19 ha yang terdiri dari S1 (sangat sesuai) seluas 561,69 ha, S2 (sesuai) seluas 208,19 ha, S3 (sesuai bersyarat) 42 ha, dan TS (tidak sesuai) 65,72 ha.

\section{Daya Dukung Perairan}

Untuk mengetahui kawasan yang bisa dijadikan pengembangan budidaya rumput laut melalui pendekatan kapasitas perairan, pendekatan kapasitas perairan dipengaruhi oleh luas areal budidaya yang sesuai (sangat sesuai dan sesuai). Daya dukung perairan di Kecamatan Bluto adalah 770,19 ha dan jumlah unit atau rakit yang dapat digunakan dengan luas tersebut adalah 42.788 unit. Menurut data dari Anonim (2012), jumlah petani rumput laut di Kecamatan Bluto sebanyak 900 orang dengan jumlah rakit 13.400 unit dan hasil produksi selama setahun sebesar 98.839,83 ton. Hasil produksi bisa ditingkatkan tanpa harus adanya degradasi lingkungan dengan memperbanyak jumlah rakit. Dengan sisa 29.388 rakit lagi yang bisa ditanam, maka dapat diasumsikan produksi rumput laut bisa bertambah sebesar 315.608,85 ton/tahun.

Hasil wawancara dan pengamatan yang dilakukan dibeberapa desa yang terdapat di Kecamatan Bluto menunjukkan bahwa rata-rata masyarakat membuang limbah baik industri atau rumah tangga dan pertanian langsung ke laut, sehingga berdampak langsung pada pencemaran dan degradasi kualitas perairan. Keberadaan kegiatan perikanan tangkap juga dapat mengganggu kegiatan budidaya rumput laut, dengan semakin banyak masyarakat yang menjadi nelayan maka semakin berkurang lahan budidaya yang tersedia. Konflik-konflik yang ditemukan di lokasi yaitu konflik antara nelayan dengan pembudidaya dan konflik keamanan. Peran serta pemerintah daerah perlu di laksanakan dalam bentuk penanggulangan konflik-konflik yang terjadi. Dari segi pencemaran lingkungan bisa diadakan sosialisasi tentang pentingnya menjaga lingkungan untuk kepentingan perekonomian bersama. Membagi zona-zona pemanfaatan perairan antara perikanan tangkap dan budidaya karena Kabupaten Sumenep dengan otonomi penuh, mempunyai peluang yang besar untuk memanfaatkan, mengelola dan melindungi wilayah pesisir dan lautannya untuk sebesarbesarnya kemakmuran rakyat (Fachrudin, 2011).

\section{KESIMPULAN}

Kegiatan budidaya rumput laut di Kecamatan Bluto Kabupaten Sumenep dapat menjadi tulang punggung perekonomian masyarakat pesisir dengan memanfaatkan luas perairan yang berpotensi, akan tetapi harus memperhitungkan aspek lingkungan dan sosial masyarakat seperti konflik kepentingan dan pemanfaatan wilayah dengan perikanan tangkap. Hasil penelitian ini merekomendasikan tentang perlunya campur tangan pemerintah dalam penyelesaian konflik dalam pemanfaatan lahan untuk perikanan tangkap dan budidaya dengan mengatur zona-zona pemanfaatan dan sosialisasi dalam pelestarian lingkungan pesisir. 


\section{DAFTAR PUSTAKA}

Anonim, 1996. Pengembangan Prototipe Wilayah Pesisir dan Marin Kupang-Nusa Tenggara Timur, Pusat Bina Aplikasi Inderaja dan Sistem Informasi Geografis, Cibinong.

Anonim, 2002. Modul Sosialisasi dan Orientasi Penataan Ruang, Laut, Pesisir dan Pulau-Pulau Kecil. Ditjen Pesisir dan Pulau-Pulau Kecil. Direktorat Tata Ruang Laut, Pesisir dan PulauPulau Kecil, Jakarta.

Anonim, 2008. Pengembangan Sentra Budidaya dan Agribisnis Rumput Laut. Dinas Kelautan dan Perikanan. Sumenep.

Anonim, 2012. The State of World Fisheries and Aquaculture. Food and Agriculture Organization of The United Nations. Rome.

Agustiningsih, D., 2012. Analisis Kualitas Air dan Beban Pencemaran Berdasarkan Penggunaan Lahan di Sungai Blukar Kabupaten Kendal. Tesis Program Magister Ilmu Lingkungan Universitas Diponegoro, Semarang.

Amarulah, 2007. Pengelolaan Sumberdaya Perairan Teluk Tamiang Kabupaten Kota Baru untuk Pengembangan Budidaya Rumput Laut (Eucheuma cottonii). Fakultas Perikanan dan Ilmu Kelautan. Institut Pertanian Bogor. Bogor.

Amosu dan Alberto, O. 2012. South African Seaweed Aquaculture: A Sustainable Development Example for Other African Coastal Countries. African Journal of Agricultural, 8(43):5268-5279.

Arisandi. 2011. Pengaruh Salinitas yang Berbeda terhadap Morfologi, Ukuran dan Jumlah Sel, Pertumbuhan serta Rendemen Karaginan Kappaphycus alvarezii. Jurnal Ilmu Kelautan, 16(3):143-150.

Ariati, R.W., Sya'rani, L dan Arini, E. 2007. Analisis Kesesuaian Perairan Pulau Karimunjawa dan Pulau Kemujan Sebagai Lahan Budidaya Rumput Laut Menggunakan Sistem Informasi Geografis. Jurnal Pasir Laut, 3(1):27-45.

Aslan, L.M. 1998. Budidaya Rumput Laut. Edisis Revisi. Penerbit Kanisius, Yogyakarta.

Burtin, P. 2003. Nutritional Value of Seaweed. Journal of Agricultural Food Chemistry, 2(4):1-6.

Dahuri, R., 1998. The Application of Carryng Capacity Concept For Sustainable Costal Resources Development in Indonesia. Jurnal Pengelolaan Sumber Daya Pesisir dan Lautan Indonesia, 1(1):22-31
Fachrudin, S.A., 2011. Potential Resources Study At Coastal Area Of Sumenep Regency. Jurnal Ilmiah Perikanan dan Kelautan, 3(2):18-28.

Gazali, I. 2013. Evaluasi Dampak Pembuangan Limbah Cair Pabrik Kertas Terhadap Kualitas Air Sungai Klinter Kabupaten Nganjuk. Jurnal Keteknikan Pertanian Tropis dan Biosistem, 1(2):1-8

Harahap, N dan Kaunang, T.D., 2011. Analisis Parameter Oseanografi di Lokasi Pengembangan Eucheuma spinosum Pulau Nain Kabupaten Minahasa Utara. Indonesian Journal of Marine Sciences, 16(4):193-198.

Harrison P. J., dan Hurd C. L. (2001) Nutrient Physiology of Seaweeds: Application of Concepts to Aquaculture. Cahiers de Biologie Marine. 42:71-82.

Kamlasi, Y. 2008. Kajian Ekologis dan Biologi Untuk Pengembangan Budidaya Rumput Laut (Eucheuma cottoni) di Kecamatan Kupang Barat Kabupaten Kupang Provinsi Nusa Tenggara Timur. Tesis Program Pasca Sarjana Institut Pertanian Bogor. Bogor

Mohammed, G. 2013. Seaweed Farming. Calicut Research Centre of CMFRI, Calicut.

Phillips, M. J. 1990. Environmental Aspects of Seaweed Culture. In Regional Workshop on the Culture and Utilization of Seaweeds. Vol. II, NACA, Bangkok.

Radiarta, I., Wardoyo, S. E., Priyono, B., dan Praseno, O. 2003. Aplikasi Sistem Informasi Geografis untuk Penentuan Lokasi Pengembangan Budidaya Laut di Teluk Ekas, Nusa Tenggara Barat. Jurnal Penelitian Perikanan Indonesia, 9(1):67-71.

Setiyanto, D., Efendi, I. dan Antara, K. J. 2008. Pertumbuhan Kappaphycus alvarezii var Maumare, var Sacol dan Eucheuma cottonii di Perairan Musi Buleleng. Jurnal Ilmu Kelautan, 13(3):171-176.

Sulistyowati, H., 2003. Struktur Komunitas Seaweed (Rumput Laut) di Pantai Pasir Putih Kabupaten Situbondo. Jurnal Ilmu Dasar, 4(1): 58-61.

Yousef, S.A., Alejandro, AA., Buschmann H., dan Kevin, M., 2012. Fitzsimmons Experiments on an Integrated Aquaculture System (Seaweeds and Marine Fish) on the Red Sea Coast of Saudi Arabia: Efficiency Comparison of Two Local Seaweed Species for Nutrient Biofiltration and Production. Aquaculture, 4:21-31.

Zoer'aini. 1992. Ekosistem Komunitas dan Lingkungan. Penerbit Bumi Aksara, Jakarta. 